Cell Research (2000), 10, 325-335

\title{
Identification and genetic mapping of four novel genes that regulate leaf development in Arabidopsis
}

\author{
Sun Yue ${ }^{1, *}$, Wei Zhang ${ }^{1, *}$, Feng Ling Li ${ }^{1}$, Ying Li Guo ${ }^{2}$, Tian \\ Lei LiU ${ }^{1}$, Hai HuANG ${ }^{1,3, * *}$ \\ 1 Shanghai Institute of Plant Physiology, Chinese Academy of \\ Science, 300 Fenglin Road, Shanghai 200032, China \\ 2 School of Life Sciences, University of Science and Technology \\ of China. P.O.Box 4, Hefei, Anhui 230027, China \\ 3 Shanghai Research Center of Life Sciences, Chinese Academy \\ of Sciences, 320 Yueyang Road, Shanghai 200031, China
}

\begin{abstract}
Molecular and genetic characterizations of mutants have led to a better understanding of many developmental processes in the model system Arabidopsis thaliana. However, the leaf development that is specific to plants has been little studied. With the aim of contributing to the genetic dissection of leaf development, we have performed a large-scare screening for mutants with abnormal leaves. Among a great number of leaf mutants we have generated by T-DNA and transposon tagging and ethylmethae sulfonate (EMS) mutagenesis, four independent mutant lines have been identified and studied genetically. Phenotypes of these mutant lines represent the defects of four novel nuclear genes designated LL1 ( LOTUS LEAF 1), LL2 ( LOTUS LEAF 2), URO (UPRIGHT ROSETTE), and EIL ( ENVIRONMENT CONDITION INDUCED LESION). The phenotypic analysis indicates that these genes play important roles during leaf development. For the further genetic analysis of these genes and the map-based cloning of LL1 and LL2, we have mapped these genes to chromosome regions with an efficient and rapid mapping method.
\end{abstract}

Key words: Arabidopsis, leaf mutant, leaf development, genetic mapping.

* Both authors contributed equally to this work.

** Corresponding author. E-mail: hhuang@iris.sipp.ac.cn; Phone: 86-21-64042090;

Fax: 86-21-64042753 
Identification and mapping of four Arabidopsis leaf genes

\section{INTRODUCTION}

Arabidopsis as a model system has been widely used in developmental biology. Major insights into developmental processes have been obtained in Arabidopsis by isolation and characterization of mutants. Some notable examples of analyses based on the characterization of large groups of mutants are those on flower and embryonic development[1-3]. In these cases, the genetic and molecular characterization of mutants has allowed the identification of genes that specify developmental cell fates and determine the final architecture of specific organs.[4] In contrast, the development of dicotyledonous plant leaves has received little attention in the way of causal analysis[5-6]. From a developmental genetic point of view, current knowledge of the leaf is far inferior to that of other plant organs or tissues, such as flowers and roots[4]. The identification of genes that control leaf development is problematic mainly for two reasons. First, the inexistence of analogous phenomena in animals can not allow us to do gene cloning by homology. Second, two important processes that take place in the leaf, photosynthesis and the exchange gases with the environment, both require the participation of a large number of gene products, many of them presumably absent or poorly represented in other plant organs [7].

In order to dissect the mechanisms underlying leaf development, we are using a genetic approach to focus on the causal analysis of gene functions, based on the isolation of Arabidopsis mutants with abnormalities in leaf morphogenesis and symptoms on leaves. After a large-scare screening by different methods such as T-DNA and transposon tagging and EMS mutagenesis, we have obtained a large number of leaf mutants. In this paper, we reported the identification and genetic characterizations of four leaf mutants from T-DNA insertion, transposon tagging, and EMS mutagenesis collections. We also reported the genetic mapping of the corresponding nuclear genes defined by mutant phenotypes.

\section{MATERIALS AND METHODS}

\section{Plant materials and plant growth}

All Arabidopsis mutants analyzed in this work are on the Landsberg erecta (L er) genetic background. Mutants lotus leaf 1 ( ll1) and lotus leaf 2 ( 1l2) were isolated from an EMS-induced population according to a protocol from Meyerowitz (http://www.caltech.edu/ $\sim$ meyerowitz/protocols/ EMS.html). Before phenotypic analysis, 1l1- 1 and ll2- 1 had been backcrossed to wild type $\mathrm{L}$ er four and three times, respectively. Mutant upright rosette ( uro) and environment condition induced lesion ( eil) were from the T-DNA and transposon tagging collections[8], respectively. Seeds were sowed in vermiculate containing PNS medium[9] and kept in $4{ }^{\circ} \mathrm{C}$ for $24 \mathrm{~h}$, then changed to $23^{\circ} \mathrm{C}$ with a photoperiod of $18 \mathrm{~h}$ light and $6 \mathrm{~h}$ dark.

\section{Genetic mapping}

Crosses between mutants (Ler) and a polymorphic strain, wild-type Columbia, were performed, and the F1 plants were selfed. For each F2 population, one single floral bud just before flowering was picked from each mutant plant (for mapping recessive mutation), or from each wild-type 
plant (for mapping semi-dominant mutation). These floral buds were then combined to prepare a DNA template. The floral bud is a relatively even-growth tissue, thus allowing each F2 individual plant equally contributes to the DNA pool. PCR-based genetic markers were selected to analyze the pooled DNAs for the initial linkage test. Once the linkage between mutations and genetic markers was established, 60 to 100 individual F2 mutant plants were further analyzed by tissue PCR[10] with at least two flanking markers to score the distance between mutations and the corresponding markers.

\section{DNA preparation}

About sixty buds were combined into a $1.5 \mathrm{ml}$ Eppendorf tube. These buds were ground manually with a teflon pestle (VWR) in $0.6 \mathrm{ml}$ lysis buffer $(0.2 \mathrm{M}$ Tris- $\mathrm{HCl}, \mathrm{pH} 8.0,7 \mathrm{M}$ urea, 50 $\mathrm{m}$ M EDTA and 2\% sarkosyl). The homogenates were extracted with phenol/chloroform (V/V, 1: 1) once, and the DNA was precipitated with isopropanol. The pellets were resuspended in $0.4 \mathrm{ml}$ $\mathrm{TE}$, and precipitated one more time with ethanol. DNA was washed with $70 \%$ ethenol once, dried, and resuspended in $100 \mu \mathrm{l} \mathrm{H}_{2} \mathrm{O}$ for PCR.

\section{$P C R$ reaction}

The published genetic markers used for PCR were: nga6, nga8, nga63, nga76, nga106, nga111, nga126, nga162, nga225, nga248, nga280[11], and the additional markers posted on internet were: nga1107, nga1126, nga1139, MBK5, and AthBIO2 [http://cbil.humgen.upenn.edu/ atgc/ SSLP-info/SSLP-assay.html;[12]. Allele-specific markers were designed according to the method described by Newton et al.[13] and Wu et al.[14]. They are D2002-1 [forward primers, 5' TCTACG CTAGACTCA GAT-3'(L er), 5' -TCTACGCTAGACTCAGGC-3'(Col); reverse primer, 5' -GGTAAGC TCTCTCTCAG-3’], D3065-1 [forward primers, 5' CTCTGTGGTTTTTAGGTGATCC-3'(L er), 5’ -TTCTGTGGTTTTTAGGTGATCG-3'(Col); reverse primer GTACGGCCCTGTGTCTTCG], D4054-1 [forward primers, 5, GTGTTCTCGAACCCTATG-3'(L er), 5' -GTGTTCTCGAACCCTA TA-3'(Col); reverse primer 5'-GGAGAATCAACCAGTGG-3'], and D5093-1 [forward primers, 5' -CTAAGACGGCTATTTGTTA-3'(L er), 5' -CTAAGACGGCTATTTGTTT-3'(Col); reverse primer 5' GGACAAAA- ACAGAGAAC-3'].

PCR reaction with DNAs from pooled Arabidopsis buds was performed in a total 50- $\mu$ l volume containing $2 \mu \mathrm{l}$ DNA (see above), $5 \mu \mathrm{l} 10 \times \mathrm{PCR}$ buffer $(0.1 \mathrm{M}$ Tris- $\mathrm{HCl}, \mathrm{pH} 8.3,0.5 \mathrm{M} \mathrm{KCl}, 15 \mathrm{~m}$ $\mathrm{M} \mathrm{MgCl}_{2}$, and $0.1 \%$ gelatin), 8 nmols of dNTP, 25 pmols of each primer, and 4 units Taq DNA polymerase. DNA samples were denatured at $95{ }^{\circ} \mathrm{C}$ for $5 \mathrm{~min}$, followed by $30-40$ cycles of amplification: $95{ }^{\circ} \mathrm{C}$ for $30 \mathrm{sec}, 56^{\circ} \mathrm{C}$ for $30 \mathrm{sec}$, and $72^{\circ} \mathrm{C}$ for $30 \mathrm{sec}$.

Arabidopsis leaf tissues were directly used for PCR as described by Klimyuk et al[10]. In brief, about two square millimeters of leaf tissue was placed in a $0.5 \mathrm{ml}$ microfuge tube containing 40 u $10.25 \mathrm{M} \mathrm{NaOH}$. The tubes were boiled for $30 \mathrm{sec}$, then $40 \mu \mathrm{l} 0.25 \mathrm{M} \mathrm{HCl}$ and $20 \mu \mathrm{l}$ buffer $(0.5 \mathrm{M}$ Tris-HCl, $\mathrm{pH} 8.0$, and $0.25 \% \mathrm{NP}-40$ ) were added. The tubes were boiled for another $2 \mathrm{~min}$, and then centrifuged at $12000 \times \mathrm{g}$ for $1 \mathrm{~min}$. Supernatant was discarded, and $50 \mu \mathrm{l}$ reaction mix (as above) was added to each tube. PCR conditions are the same as described previously (see above). Length polymorphism between PCR products was assessed by analyzing $10 \mu \mathrm{l}$ reactions on a $1 \%$ to $3.5 \%$ agarose gel[12].

\section{Light and scanning electron microscopy}

Phenotypic analysis by light and scanning electron microscopy (SEM) was performed according to our previous methods[15].

\section{RESULTS}


Identification and mapping of four Arabidopsis leaf genes

\section{Identification and genetic characterization of $l l 1$ and $l l 2$ mutants}

In the course of screening Arabidopsis mutants with abnormal leaf phenotypes, one leaf mutant was identified from the progeny of EMS mutagenesis lines. Although this mutant has pretty normal cotyledons as shown in Fig 1A, its rosette leaves are defective. Instead of the petiole growth on one side of lamina in wild-type (Fig 1A, B, left), petioles of some early arising leaves in this mutant grow underneath laminae (Fig 1A, middle), displaying a lotus-leaf-like phenotype (pointed by arrows). This mutant, designated lotus leaf 1- 1 (111-1), has a smaller size (Fig 1A, middle) in comparison with that of the wildtype plant (Fig 1A, left). Genetic analysis indicated that 1l1- 1 is a single-gene recessive nuclear mutant, because the F1 plants from a cross between 1l1- 1 and wild-type were normal, and F2 progeny segregated wild-type to ll1- 1 mutants with a 3 to 1 ratio (136 wild-type plants versus 44 mutant plants).

In order to have a better understanding of the LL1 gene functions during leaf development, we extended our mutant screening for more 111 alleles. Four additional independent mutant lines with overall similar phenotype to that of ll1- 1 were identified. The result of allelism test among these mutants revealed that they could be classified into two complementation groups. In the ll1- 1 group, there were two more alleles, designated 111- 2 and 111- 3. In the complemented group, two lotus-leaf mutants were named l12- 1 (Fig 1A, right) and 112- 2, respectively. The later arising rosette leaves in 111 (Fig 1B middle) and 112 (Fig 1B right) mutants do not show a lotus-leaf structure. However, they are broad at the basal part of the lamina in comparison to that of wild-type (Fig 1B, left), and weakly wrinkled, with the margins unevenly curled downwards (Fig 1B, middle and right). Likewise, the 112 phenotype is also caused by the defect of a single nuclear recessive gene with the F2 phenotypic segregation of 139 wild-type plants and 43 mutants, which is close to a $3: 1$ ratio.

To determine when the LL1 and LL2 proteins are required for the normal leaf development, we analyzed leaf phenotypes at different developmental stages in 111 and 112 by SEM. The abnormalities of 111 and 112 leaves appear at very early developmental stages, when primordia of the first rosette leaves initiate. Although the leaf primordial shapes are similar between the wild-type and mutants, developmental processes of leaf primordia seem slower in 111 and 112 mutants. In wild-type plants, the first two leaf primordia form completely by $\mathrm{d} 3$ postgermination (Fig $2 \mathrm{~A}$ ). These primordia develop as radially symmetric structure on opposite sides of a rectangular shoot apical meristem. Stipules, the paired leafy appendages, begin to emerge between $\mathrm{d} 4$ and $\mathrm{d} 5$ at the base of leaves. At this stage leaf primordia grow with an attached manner (Fig 2B). In 111 (Fig 2C) and 112 (Fig 2D), however, although stipules have emerged by $\mathrm{d} 4$ postgermination, the leaf primordia are smaller in size and grow separately. The abnormal leaf primordia indicate that LL1 and LL2 are proteins required at very early leaf developmental stages.

\section{Semi-dominant leaf mutant uro}

In about 1400 independent T-DNA transgenic lines, a mutant with abnormal rosette 
Sun $\mathrm{Y}$ et al.
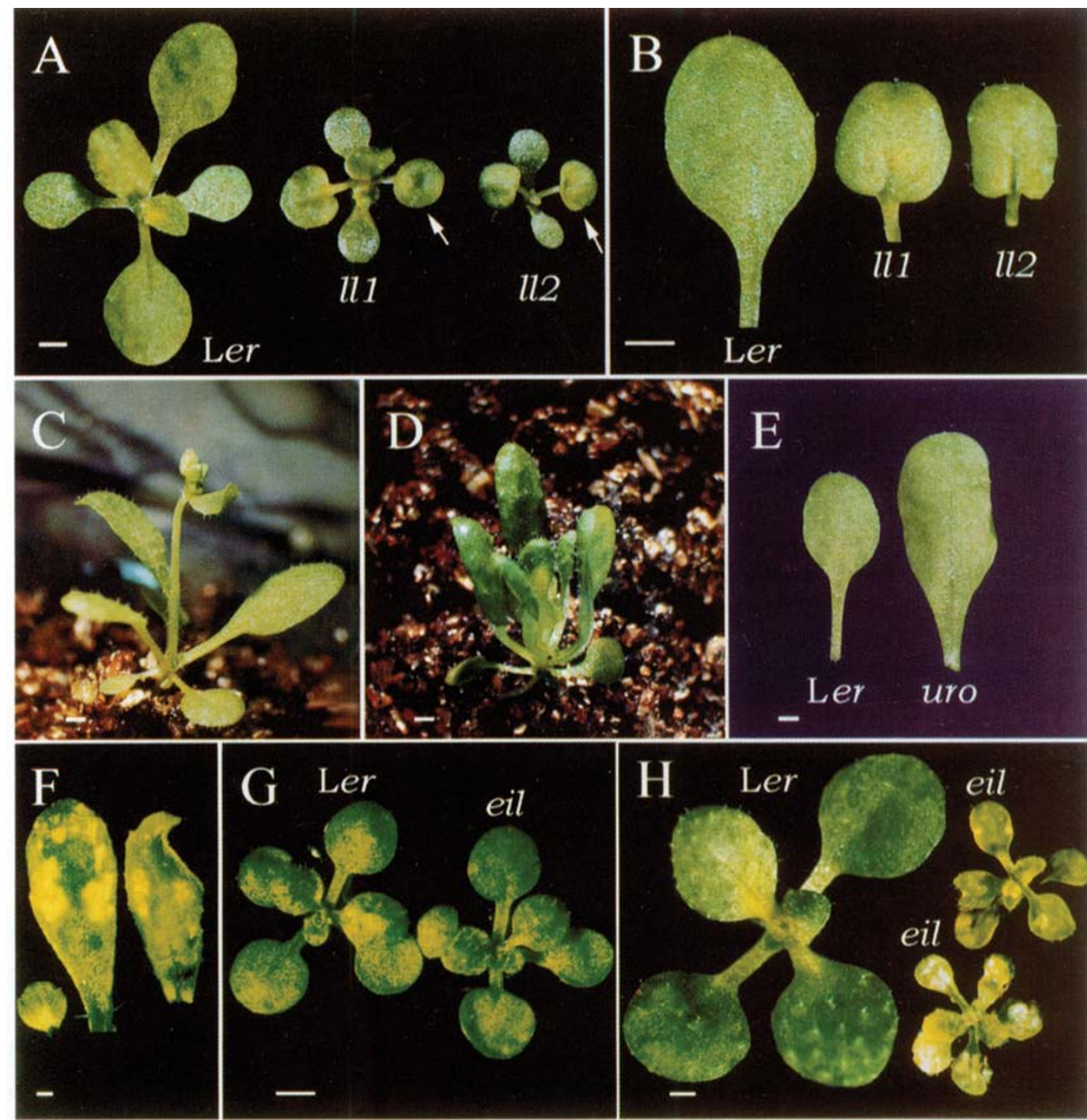

Fig 1. Phenotypes of leaf mutants. A. Seedlings of wild-type Ler (left), ll1- 1 (middle), and ll2- 1 (right). All plants were at the same developmental stage. Arrows point the rosette leaves with a lotus-leaf structure. B. Same-stage rosette leaves of wild-type L er (left), ll1- 1 (middle), and ll2- 1 (right). C. A wild-type plant. D. An uro mutant plant. Note: the rosette leaves of uro are upright. The plants in $\mathrm{C}$ and $\mathrm{D}$ were at the same age. E. Wild-type (left) and uro (right) rosette leaves. F. Lesions appeared on all kinds of eil leaves at $25^{\circ} \mathrm{C}$ : cotyledon (left), rosette leaf (middle), and cauline leaf (right). G. Wild-type and eil mutant plants grew at $19^{\circ} \mathrm{C}$. H. Wildtype and eil mutant plants grew at $25^{\circ} \mathrm{C}$. Scare bars are $1 \mathrm{~mm}$ in A to $\mathrm{E}$, and $2 \mathrm{~mm}$ in $\mathrm{F}$ to $\mathrm{H}$.

leaves in a wild-type plant usually grow with a small angle to the ground during early seedling stage (Fig 1C). In the mutant, however, the early-appeared rosette leaves at the same stage are upright (Fig 1D). Therefore this mutant was named upright rosette ( uro). 


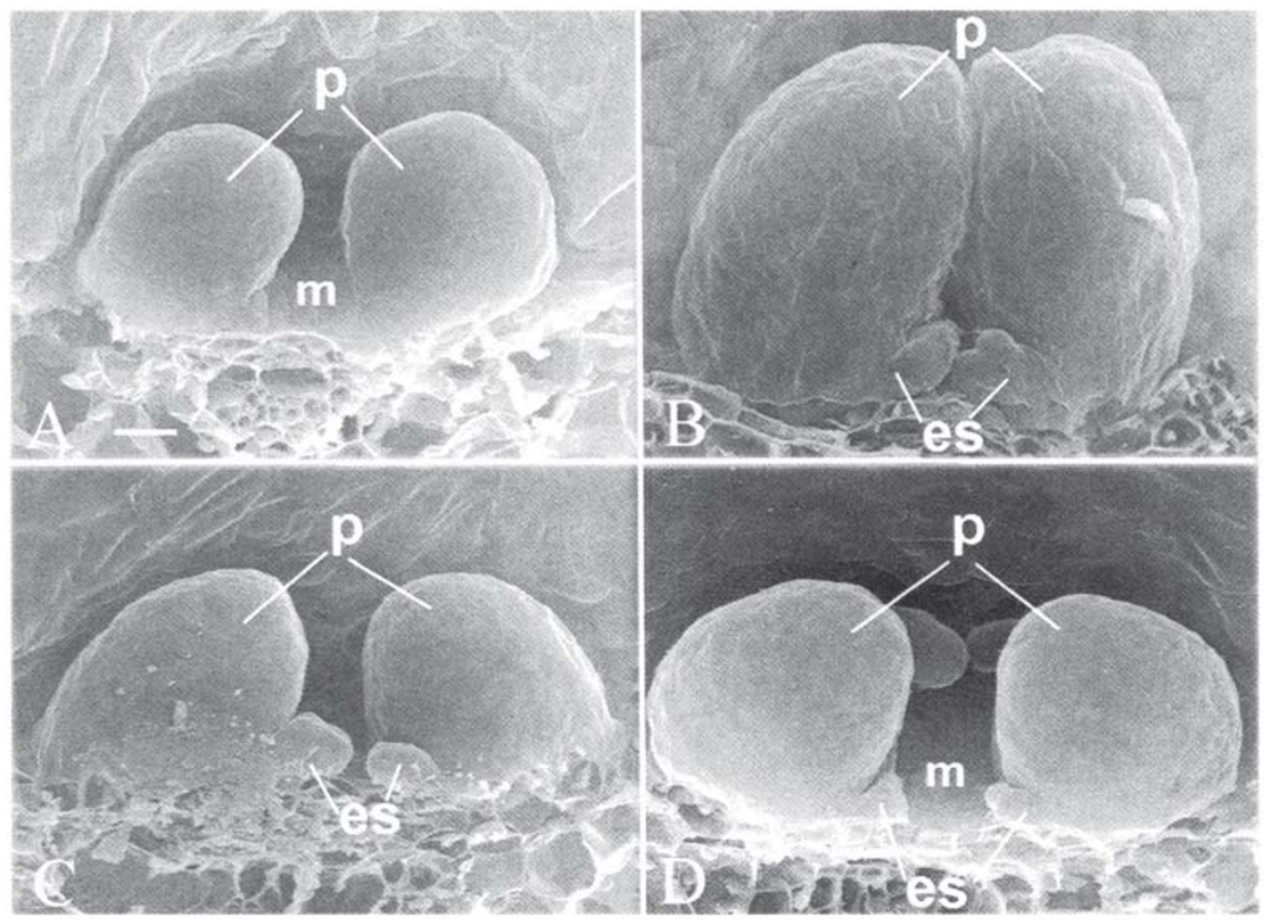

Fig 2. SEM of leaf primordia of wilt-type $L$ er and 111 and 112 mutants. A. L er, d 3 postgermination. B. L er. C. $l l 1$. D. $l l 2$. Leaf primordia in images B to D are from plants by d 4 postgermination. All images have the same magnification. p, leaf primordium; m, shoot apical meristem ; es, stipule. Bar $=10 \mu \mathrm{m}$.

The whole plant stature of uro mutant seems very compacted with a dwarf phenotype. In contrast to wild-type L er (Fig 3, left), uro produces many reproductive branches but lacks a dominant one (Fig 3, middle and right). The rosette leaves in a more mature uro plant turn to grow with a small angle to the ground, similar to those in the wild-type (Fig 3), however the laminae are mostly contortive (Fig 1E, right).

The uro phenotype is caused by a single-gene semi-dominant nuclear mutation. The F1 generation from a cross between wild-type and uro displayed a little weaker uro phenotype (Fig 3, middle), and F2 generation segregated normal-to-mutant plants with a 1: 3 ratio (159 wild-type plants and 459 mutant plants). Among F2 mutant plants, about one third showed more severe uro phenotypes: they were shorter than F1 heterozygotes and poorly fertile with minimum seeds set (Fig 3, right). The less severe uro plants were subsequently demonstrated to be the heterozygotes, while the severe ones were the homozygotes, because there is a further phenotypic segregation from the progeny of the less severe uro but not from those of the severe one (data not shown). Co-segregation analysis was performed using seeds from 302 wild-type-like lines of the F2 segregation population. All progenies from each of those lines were kana- mycin sensitive, indicating 
that the T-DNA insertion is tightly linked to the uro mutation.

Environment-condition dependent phenotype in eil

Mutant eil was identified from the transposon tagging system [8] with phenotypes showing undetermined lesions on leaves. In the common Arabidopsis growth conditions, these lesions can be formed at very early developmental stages, appearing on various kinds of, leaves such as cotyle- dons (Fig $1 \mathrm{~F}$, left), rosette (Fig $1 \mathrm{~F}$, middle) and

Fig 3. Comparison of plant statures between wilt-type 1 er and uro mutants. Left, wilt-type L er. Middle, plant heterozygous for URO. Right, plant homozygous for URO. Note, both uro/+ and uro/ uro plants lack a dominant inflorescence. All plants were at the same growth stage. Bar $=1 \mathrm{~cm}$.

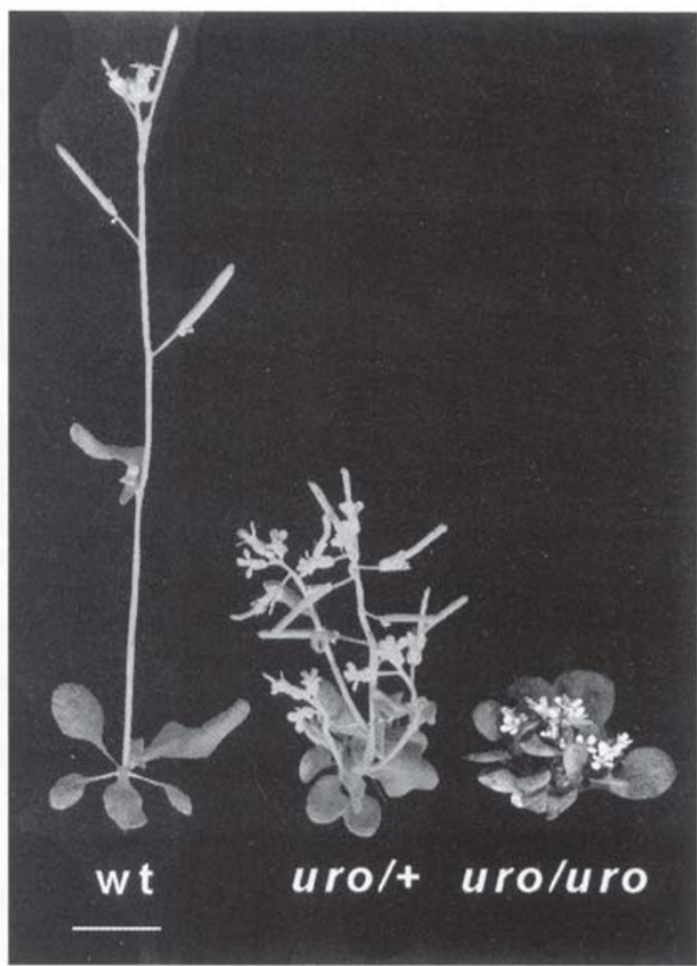

cauline leaves (Fig 1F, right). Unlike previously isolated lesion mimic mutants in Arabidopsis[16],[17], the expression of eil phenotypes depends on environment conditions including temperature, photoperiod of time and intensity of light. At $19^{\circ} \mathrm{C}$ or lower, eil plants were indistinguishable from wild-type plant (Fig 1G). However, when eil plants were grown at $22^{\circ} \mathrm{C}$, which is the common temperature for Arabidopsis growth, lesions appeared. When eil was grown at $24^{\circ} \mathrm{C}$, the plants were severely affected, resulting in very sick and badly developed plants (Fig $1 \mathrm{H})$. Shorter photoperiod and low intensity of light can also greatly reduce symptoms on eil leaves (data not shown).

Genetic analysis demonstrated that eil phenotype was heritable. F1 plants from a cross between eil and wild-type showed the wild-type phenotypes, indicating that the eil mutation is recessive. F2 progeny showed a 3:1 (387 wild-type and 124 eil mutant) segregation ratio, suggesting eil mutant phenotype is due to a single nuclear gene defect.

In order to know the more detailed mutant phenotype at the cellular level, we analyzed leaf sections using same-stage seedling leaves from wild-type and eil mutant. We first examined cells in the green region of an eil leaf. The cellular pattern between wildtype (Fig 4A, upper) and eil (Fig 4A, lower) seemed similar. However, the cell size in eil leaf was dramatically reduced. The smaller cell size might be caused by a secondary effect, as photosynthesis and other physiological activities can all affect lesion initiation. We then studied the time course of lesion formation in eil rosette leaves. When eil plants 
Identification and mapping of four Arabidopsis leaf genes

A
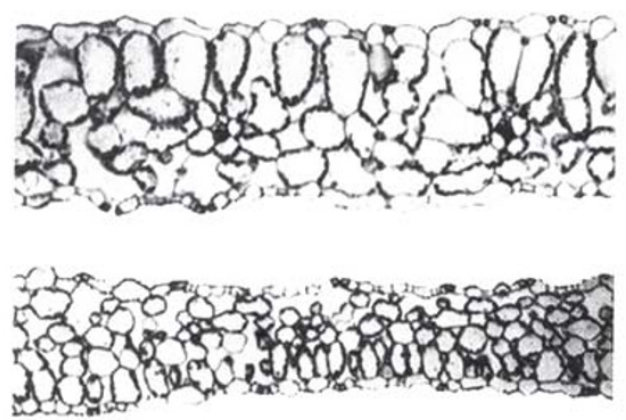

$\mathrm{B}$
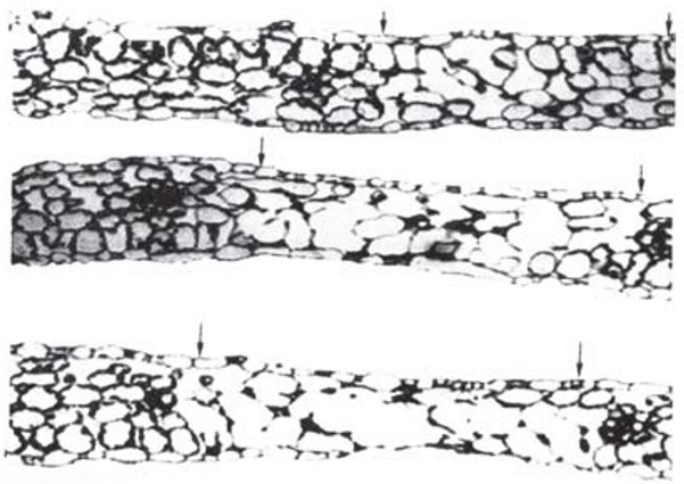

Fig 4. Cross section to analyze rosette leaf cells in eil mutants. A. Top, wild-type L er. Bottom, eil mutant. The section was prepared using green tissue from an eil leaf, from which lesions had already appeared. Both wild-type and mutant leaves were at the same growth stage. B. Lesions developed from earlier stage (top), middle stage (middle) and later (bottom) stages. Cells between arrows are those within lesions. Bar $=75 \mu \mathrm{m}$.
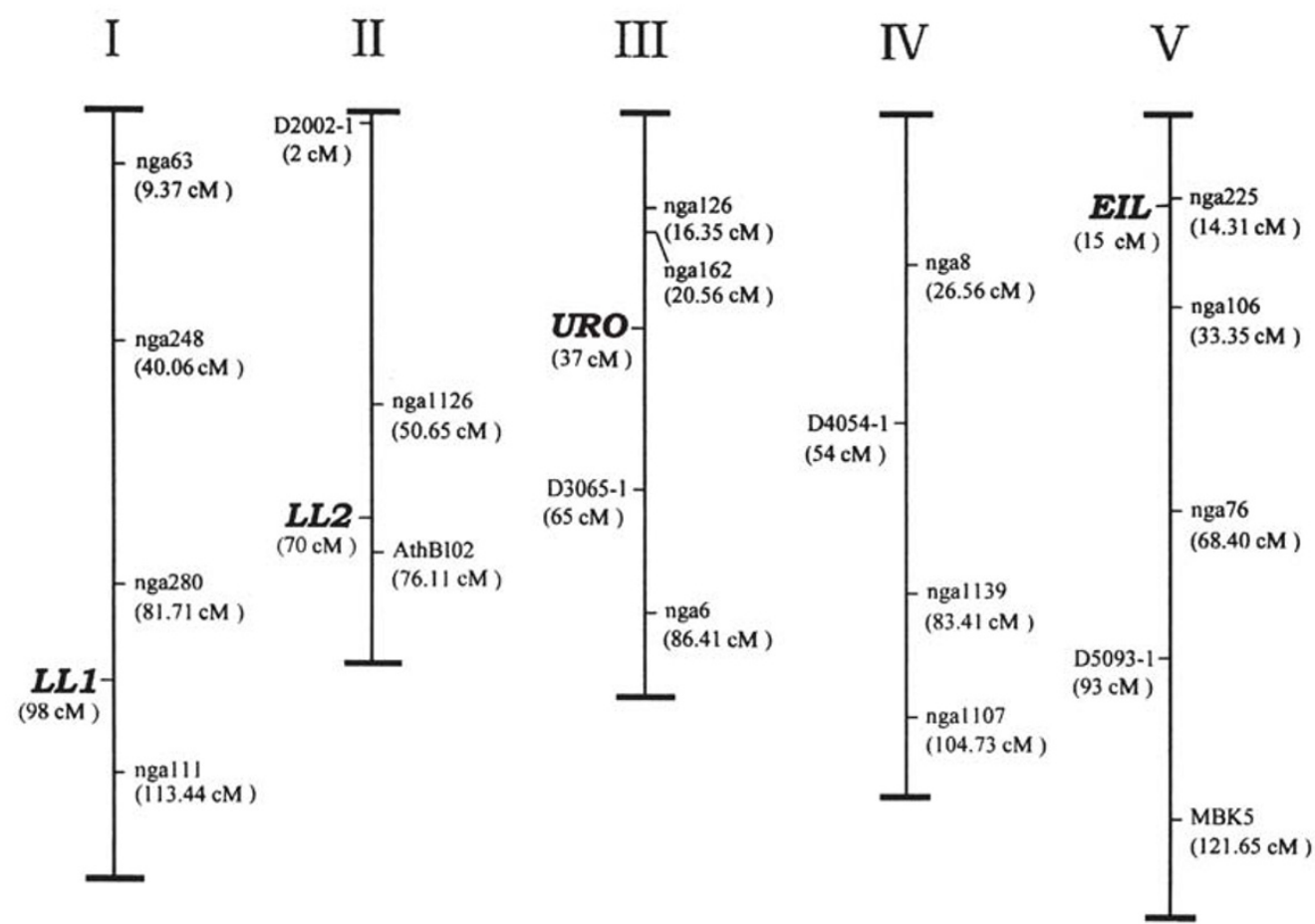

Fig 5. Map positions of LL1, LL2, URO, and EIL. The vertical lines represent Arabidopsis chromosomes. Genetic markers right to vertical lines are the published SSLP markers, and those left to the vertical lines are the allele-specific markers. Genes mapped are in bold-face. Linkage map is based on RI data generated by Lister et al, which appeared on web site http: //arabidopsis. org/cgi- bin/maps/Riintromap. 
were grown at $25^{\circ} \mathrm{C}$, cells in the lesion area started to die. At the later stage, the protoplasts were shrunk and diminished, left big empty cavities (Fig 4B).

\section{Genetic mapping of the newly identified genes}

To further study these leaf mutants and eventually clone the genes, we conducted genetic mapping to determine their map positions. First, we chose 16 SSLP markers in different chromosome regions for initial linkage analysis, due to the convenience of those markers in genotyping. For the chromosome regions where there are no such SSLP markers available, we identified 4 single nucleotide polymorphisms and synthesize allelespecific markers instead[13-14]. These 20 PCR-based genetic markers were assigned relatively evenly throughout the Arabidopsis genome (Fig 5). With these markers we have mapped LL1, LL2, URO and EIL to different chromosomes, respectively (Fig 5).

\section{DISCUSSION}

During the past decades, a vast inventory of Arabidopsis mutants has been constructed by the efforts of international Arabidopsis research community. Such a large collection of Arabidopsis mutants represents an indisputable treasure for research project devoted to the genetic dissection of plant development. To address the question of how leaf development is processed, the most useful approach is the identification, characterization, and manipulation of genes that are candidates for controlling leaf development. Those genes can be defined by the analysis of mutant phenotypes. With T-DNA and transposon tagging, and EMS mutagenesis, we have established a large Arabidopsis leaf mutant population, among which four leaf mutants representing the defects of four novel genes have been studied.

LL1 and LL2 genes appear to regulate a same developmental pathway, because the mutation in each of these two genes resulted in very similar leaf phenotypes. Although the earliest abnormalities we have observed in 111 and 112 leave appear at the stage of leaf primordia emerge, we hypothesized that the LL1 and LL2 gene functions may be required even earlier. The fact that the region between two leaf primordia in mutants is wider than that in the wide-type indicates that the apical meristem may be abnormal. Therefore, before leaf primordia emerge, the shoot apical meristem, which produces leaves, has already required the function of LL1 and LL2 proteins. In the wild-type, plant apical meristem gives rise to the first pair of leaf primordia that grow separately at $d 3$ postgermination. Between d 4 and d 5, the leaf primordium growth is in an attached manner. In 111 and 112 mutants, however, the separate growth of leaf primordia lasts longer. This result suggests that the LL1 and LL2 are still required in the following leaf development processes. The broad lamina of 111 and 112 indicates that they might be affected in the patterns of cell division, or in the lateral control of cell expansion, as is observed in a previously reported mutant rotundifolia[18].

Based on the phenotypic observations in uro mutant, we hypothesized that cells 
Identification and mapping of four Arabidopsis leaf genes

on the abaxial side grow faster than those on the adaxial side at the basal part of petiole. Some asymmetric growth in plant is thought due to an unevenly distribution of plant hormone, auxin, as shown in phototropism[19] and gravitropism[20]. We thus proposed that the unevenly growth at abaxial and adaxial of uro petioles may be caused by auxin synthesis or transport defects. That there is no shoot apical dominance in uro plant provides additional evidence that the auxin synthesis or transport in uro is defective.

During leaf development, EIL gene may play a very important role in plants to resist to unfavorable environment conditions. Loss-of-function in EIL causes plants to be more sensitive to the temperature, the time of photoperiod, and the light intensity, and the normal growth conditions for the wild-type plant become the stress ones for eil mutant. It is likely that EIL may function to regulate the elimination of reactive oxygen species (ROS) during leaf development. First, lesion appearance on leaves of many species accompanies the accumulations of ROS[21]. Second, it is known that temperature, photoperiod, and light intensity have different effects on plant, however, high temperature and higher light intensity can all result in an increase of ROS[22-23]. Lesions can appear with the treatment of higher intensity of light even in wilt-type Arabidopsis[23]. We hypothesized that when EIL is defective, plants will reduce the ability to clean out the ROS, and the accumulation of ROS eventually results in the lesion formation on leaves.

\section{ACKNOWLEDGEMENTS}

We thank Chang Bin CHEN for 1l2- 1 mutant seeds, Min Huan ZENG for ll1- 2 seeds, and Xiao Dong XU for 111- 3 and 112- 2 seeds, and Jian Ping MAO for technical assistance in SEM analysis. We are grateful to Shanghai Research Center of Life Sciences, Chinese Academy of Sciences for partial financial support. This work was supported by a grant from the Chinese Academy of Sciences, KJ951-B1-604 and a National Distinguished Young Scholar Award to Hai HUANG.

\section{REFERENCES}

[1] Weigle D, Meyerowitz EM. The ABCs of floral homeotic genes. Cell 1994; 78:203-9.

[2] Yang W, Sundaresan V. Genetics of gametophyte biogenesis in Arabidopsis. Current Opinion in Plant Biology 2000; 3:53-7.

[3] Jurgens G, Mayer U, Torres RRA, Berlenth T, Misera S. Genetic analysis of pattern formation in the Arabidopsis embryo. Development Suppl 1991; 1:27-38.

[4] Serrano-Cartagena J, Robles P, Ponce MR, Micol JL. Genetic analysis of leaf form mutants from the Arabidopsis information service collection. Mol Gen Genet 1999; 261:625-739.

[5] Brutnell TP, Langdale JA. Signals in leaf development. Adv Bot Res 1998; 28:36-42.

[6] Van Lijsebettens M, Clarke J. Leaf development in Arabidopsis. Plant Physiol. Biochem 1998; 36:4760.

[7] Berna G, Robles P, Micol JL. A mutational analysis of leaf morphogenesis in Arabidopsis thaliana. Genetics 1999; 152:729-42.

[8] Sundaresan V, Springer P, Volpe T, Haward S, Jones JD, Dean C, Ma H, Martienssen R. Patterns of gene action in plant development reveared by enhancer trap and gene trap transposable elements. Genes Devel 1995; 9:1797-810. 
[9] Estelle MA, Somerville CR. Auxin-resistant mutants of Arabidopsis thaliana with an altered morphology. Mol Gen Genet 1987; 206:200-6.

[10] Klimyuk VI, Carrol BJ, Thomas CM, Tones JDG. Alkali treatment for rapid preparation of plant material for reliable PCR analysis. Plant J 1993; 3:493-4.

[11] Bell CJ and Ecker JR. Assignment of 30 microsatellite loci to the linkage map of Arabidopsis. Genomics 1994; 19:137-44.

[12] Li F, Flangan CA, Zhao Y, Ma H, Huang H. Assignment of 44 Ds insertions to the linkage map of Arabidopsis Plant Mol Biol Reporter 1999; 17M:109-22.

[13] Newton CR, Granham A, Hoptinstall LE, Powell SJ, Summers C, Kalsheker N, Smith JC, Markham AF. Analysis of any mutation in DNA. The amplification refractory mutation system (ARMS). Nucleic Acids Res 1989; 17:2503-16.

[14] Wu DY, Ugozzoli L, Pal BK, Wallace RB. Allele-specific enzymatic amplification of B-globin genomic DNA for diagnosis of sickle cell anemia. Proc Natl Acad Sci USA 1989; 86:2757-60.

[15] Chen C, Wang S, Huang H. LEUNIG has multiple functions in gynoecium development in Arabidopsis. genesis $2000 ; 26: 42-54$.

[16] Dietrich RA, Delaney SJ, Ward ER, Ryals JA, Dangl J. Arabidopsis mutants simulating disease resistance response. Cell 1994; 77:565-77.

[17] Greenberg JT, Ausubel FM. Arabidopsis mutants compromised for the control of cellular damage during pathogenesis and aging. Plant J 1993; 4:327-42.

[18] Tsuge T, Tsukaya H, Uchimiya H. Two independent and polarized processes of cell elangation relate leaf blade expansion in Arabidopsis thaliana (L.). Heynh. Development 1996; 122:1589-600.

[19] Sakai T, Wada T, Ishig uro S, Okada K. RPT2. A signal transducer of the phototropic response in Arabidopsis. Plant Cell 2000; 12:225-36.

[20] Luschnig C, Gaxiola RA, Grisafi P, Fink GR. EIR1, a root specific protein involved in auxin transport, is required for gravitropism in Arabidopsis thaliana. Genes and Dev 1998; 12:2175-87.

[21] Karpinski S, Reynolds H, Karpinski B, Wingsle G, Creissen G, Mullineaux P. Systemic signaling and acclimation in response to excess excitation energy in Arabidopsis. Science 1999; 284:654-7.

[22] Pennell RI, Lamb C. Programmed cell death in plant. Plant Cell 1997; 9:1157-68.

[23] Foyer CH, in Oxidative stress and the molecular biology of antioxident defence. Scandalios JG ed. Cold Spring Harbor Laboratory Press, Plainview, NY. 1997. pp. 587-622.

Received July-3-2000. Revised Oct-18-2000. Accepted Oct-25-2000. 